\title{
Autonomic Neuropathy in Healthy Elderly Person
}

\author{
Taslima Islam¹, Noorzahan Begum², Sultana Ferdousi ${ }^{3}$
}

\begin{abstract}
Background: Cardiac autonomic nerve function can be affected in older age. Objective: To find out the degree of autonomic neuropathy by autonomic nerve function scoring system in apparently healthy elderly subjects. Methods: This cross sectional study was conducted in the Department of Physiology, BSMMU, Dhaka between July 2005 and June 2006.For study group, 30 elderly subjects age ranged from 51-60 years were enrolled in one group whereas another 30 elderly subjects age between 61-70 years were enrolled in another group. For comparison sex and BMI matched thirty apparently healthy adults with age from 21-30 years were studied as control. Autonomic nerve function status of all the subjects were examined by five simple non-invasive cardiovascular reflex tests Valsalva maneuver deep breathing test, orthostatic test handgrip test, and sudden standing. Autonomic nerve function (ANF) scoring was done to find out the degree of autonomic neuropathy. Results: $23.34 \%$ of subjects of 61-70 years group showed autonomic nerve dysfunctions and 20\% had early involvement and $3.34 \%$ of them had definite involvement of Autonomic neuropathy. But this percentage was relatively less (10\%) in 51-60 years who had early involvement and none had found definite involvement whereas autonomic nerve function was normal in 21-30 years age group.. Conclusion: From this study, it can be concluded that aging process substantially impaired cardiovascular autonomic nerve function.
\end{abstract}

Key Wards: Autonomic neuropathy, cardiovascular reflex tests, autonomic scoring, aging.

Bangladesh Soc Physiol. 2013, December; 8(2): 77-83

For Authors Affiliation, see end of text.

http://www.banglajol.info/index.php/JBSP

\section{Introduction}

utonomic nervous system plays
important role in homestasis.
Progressive decrement of all body functions are associated with aging process, ${ }^{2}$ which also affects autonomic nerve function. ${ }^{3,4}$ This leads to subsequent age related changes in heart rate $(\mathrm{HR})$, blood pressure $(\mathrm{BP})$ regulations which ultimately may lead to the development of many cardiovascular diseases. ${ }^{5}$

Both the sympathetic and parasympathetic division of autonomic nervous system play vital role for the maintenance of constant internal environment. ${ }^{6}$

Received July 2013; $\quad$ Accepted October 2013
However, with aging process, both the systems are affected, ${ }^{6}$ and the involvement of parasympathetic change is more frequent than sympathetic. ${ }^{7}$

The parasympathetic tone and baroreflex sensitivity are reduced with advancing age. ${ }^{8}$ Although circulatory norepinephrine level is increased but its responsiveness to target organ is reduced ${ }^{9-11}$ and $\beta$ adrenergic chronotopic response, vasodilator response as well as á adrenergic vasoconstrictor response are also reduced in elderly person. ${ }^{12,13}$

In the early 1980, Ewing et all proposed five simple non-invasive cardiovascular reflex tests which 
helped to diagnose autonomic neuropathy successfully. These are heart rate (HR) response to valsalva maneuver, heart rate response to deep breathing and heart rate response to standing for assessment of parasympathetic functions and blood pressure (BP)response to standing and blood pressure response to sustained handgrip for sympathetic functions. ${ }^{14}$ On the basis of the results of these cardiovascular reflex tests, autonomic nerve dysfunction (scoring of ANF) can be categorized into early involvement, definite involvement, severe involvement and atypical pattern. ${ }^{15}$

A study reported early involvement of autonomic nerve function in some of the elderly subjects while a few number of elderly subjects had suffered from definite involvement. ${ }^{8}$ Valsalva ratio was found reduced with increasing age. ${ }^{16}$ Normally during deep breathing HR is increased more than 16 breaths per minute ${ }^{15}$ but this HR variation to deep breathing is decreased progressively with the increasing age. ${ }^{17}$ Again, HR response to standing up i.e. $30^{\text {th }}: 15^{\text {th }}$ ratio is relatively lower in healthy elderly person. ${ }^{18-19}$ Blood pressure response to standing up showed increased fall of BP in $16 \%$ of healthy person after the age of 65 years. ${ }^{17}$ Sustained handgrip causes a significant rise in diastolic BP usually more than $16 \mathrm{mmHg}$ but its magnitude is relatively lower in elderly people. ${ }^{20}$

About 15 percent of the current world population exceeds 60 years. ${ }^{8}$ Some of them may have autonomic nerve dysfunction which may be the underlying causes of many diseases especially cardiovascular diseases. Unfortunately most of them remained unnoticed and usually treated without knowing the underlying etiology. With the above background scoring of autonomic nerve function is important. Though few investigations have been undertaken in different countries, no data in Bangladeshi aged population has been published. Therefore the present study was conducted to find out the presence of any impairment of the autonomic function in this age group by scoring the results of autonomic nerve function tests in healthy elderly person in our population.

\section{Methods}

This cross sectional study was conducted in the Department of Physiology, Bangabandhu Sheikh Mujib Medical University (BSMMU), Dhaka from July 2005 to June 2006 and the protocol of this study involving human subjects was approved by the ethical review committee of the department of Physiology of BSMMU. Sixty apparently healthy elderly subjects of both sexes were selected as study group and divided into -Group $\mathrm{B}$, consisting of 30 elderly subjects age 51-60 years and Group C consisting of another 30 elderly subjects age between 61-70 years. They were selected from a slum area of Malibag, Wireless gate and BSMMU staff quarter, Paribag, Dhaka. For comparison sex and BMI and socioeconomic status matched 30 healthy adults age $21-30$ years were studied as control (Group A) from the same area. All of the subjects were belonged to lower socioeconomic status. Subjects having the history of chronic renal failure, diabetes mellitus, hypertension, heart disease, cardiac failure and neurological disorder were excluded. Before inclusion in the study, the objectives of the study were explained to all the subjects and their voluntary participation was encouraged. A written informed consent was taken from each subject. A detail medical, family, personal and socioeconomic history were recorded in a prefixed data schedule. A thorough clinical examination was done. Height and weight of the subjects were recorded and BMI was calculated. The Random blood sugar and serum creatinine were estimated for to exclude diabetes mellitus and renal failure. Subjects were asked to attend the laboratory of Department of Physiology as per schedule and their five simple non-invasive cardiovascular reflex tests were done to evaluate the autonomic nerve function. For parasympathetic function: Heart rate response to Valsalva maneuver (valsalva ratio), Hear rate response to deep breathing, heart rate response to standing $\left(30^{\text {th }}: 15^{\text {th }}\right)$ and for sympathetic function, Blood pressure response to sustained handgrip, blood pressure response to standing were measured. Based on the results of these tests, scoring of ANF was done to detect presence or absence and also the degree of autonomic neuropathy according to Bannister. ${ }^{15}$

Values for autonomic nerve function tests are given in Table I. 
Table I: for Autonomic Nerve Functions Tests ${ }^{15}$

\begin{tabular}{llccc}
\hline Tests & Measurement & \multicolumn{3}{c}{ Defined values } \\
\cline { 3 - 5 } & & Normal & Border line & Abnormal \\
\hline Valsalva Maneuver & Valsalva ratio & $>1.21$ & $1.11-1.20$ & $<1.10$ \\
HR response to standing & $30^{\text {th: }} 15^{\text {th }}$ beat ratio & $>1.04$ & $1.01-1.03$ & $<1.00$ \\
HR response to & Max-Min HR $/$ min & $>15$ & 11.14 & $<10$ \\
$\begin{array}{l}\text { deep breathing } \\
\text { BP change to }\end{array}$ & Fall in systolic BP & $<10$ & 11.29 & $>30$ \\
$\begin{array}{l}\text { Standing } \\
\text { BP change to }\end{array}$ & (mm of Hg) & & & \\
sustained Hand-grip test & Rise in diastolic & $>16$ & 11.15 & $<10$ \\
\hline
\end{tabular}

\section{Autonomic nerve function (ANF) scoring system}

Autonomic neuropathy can be classified according to the severity of damage into five groups ${ }^{15}$.

- Normal-all five tests normal or one on border line.

- Early involvement-one of the three heart rate tests abnormal or two border line.

- Definite involvement-two or more of the heart rate tests abnormal.

- Severe involvement-Two or more of the heart rate tests abnormal plus one or both of the blood pressure tests abnormal or both border line.

- Atypical pattern-Any other combination of abnormal test.

Data were expressed as mean+ SD. One way ANOVA and independent sample $t$ test were used for statistical analysis.

\section{Results}

The mean $( \pm \mathrm{SD})$ of age, height, weight and BMI of the different groups are shown in Table II. Except age all the groups were matched for height, weight, BMI.
Mean values of valsalva ratio, heart rate response to deep breathing and $30^{\text {th }}: 50^{\text {th }}$ ratio were significantly $(\mathrm{p}<0.001)$ lower in elderly subjects (51-60 years, 61-70 years) in comparison to those of lower age controls (21-30 years). Moreover, heart rate response to deep breathing was significantly $(\mathrm{p}<0.01)$, but, valsalva ratio and $30^{\text {th }}: 50^{\text {th }}$ ratio were non-significantly lower in 6170 years of subjects than those of 51-60 years subjects (Table II). Again, rise in diastolic blood pressure after sustained handgrip was significantly $(\mathrm{p}<0.05)$ lower in elderly subjects than those of young adult. Whereas, this value was similar and showed no significant difference between two elderly groups of subjects (Table III). However, fall in systolic blood pressure after standing from lying was significantly $(p<0.05)$ higher only in the subjects of 61-70 years compared to that of healthy adults (Table V). These results of parasympathetic and sympathetic function are published in our previous publications ${ }^{16-17}$. Moreover, $23.34 \%$ of subjects of 61-70 years group showed autonomic nerve dysfunctions. But this percentage was relatively less (10\%) in 51-60 years and all test results were normal in 21-30 years. In 61-70 years, early involvement of ANF was relatively more $(20 \%)$ than that of $51-60$ years of age $(10 \%)$. Again 61-70 years of subjects had a small percent (3.34\%) of definite involvement of ANF but none had found in 51-60 years. 
Table II: Age, Height, weight and body mass index (BMI) in different groups ( $\mathrm{n}=90)$

\begin{tabular}{lcccc}
\hline Groups & Age (years) & Height $(\mathrm{cm})$ & Weight $(\mathrm{kg})$ & BMI $\left(\mathrm{kg} / \mathrm{m}^{2}\right)$ \\
\hline $\mathrm{A}(\mathrm{n}=30)$ & $26 \pm 2.67$ & $161 \pm 7.93$ & $52 \pm 5.28$ & $20.22 \pm 1.83$ \\
$\mathrm{~B}(\mathrm{n}=30)$ & $56 \pm 2.68$ & $159 \pm 7.33$ & $52 \pm 5.31$ & $22.77 \pm 2.12$ \\
$\mathrm{C}(\mathrm{n}=30)$ & $66 \pm 2.97$ & $158 \pm 7.11$ & $52 \pm 5.82$ & $20.81 \pm 1.96$ \\
\hline
\end{tabular}

Group A= 21-30 years of adults (Control), Group B= 51-60 years of elderly subjects (study), Group $\mathrm{C}=61-70$ years of elderly subjects (study). $* * *=\mathrm{p}<0.001$, ns $=$ not significant, $\mathrm{n}=$ number of subjects.

Table III: Assessment of parasympathetic nerve functions in different groups (n-90)

\begin{tabular}{lccc}
\hline Groups & \multicolumn{3}{c}{ Heart rate response } \\
\cline { 2 - 4 } & $\begin{array}{c}\text { To Valsalva maneuver } \\
\text { (Valsalva ratio) }\end{array}$ & $\begin{array}{c}\text { To deep breathing } \\
(\text { rate } / \mathrm{min})\end{array}$ & $\begin{array}{c}\text { To standing } \\
\left(30^{\text {th }}: 15^{\text {th }}\right)\end{array}$ \\
\hline $\mathrm{A}(\mathrm{n}=30)$ & $1.50 \pm 0.23$ & $25.36 \pm 3.90$ & $1.10 \pm 0.06$ \\
$\mathrm{~B}(\mathrm{n}=30)$ & $1.32 \pm 0.14$ & $18.82 \pm 3.35$ & $1.05 \pm 0.03$ \\
$\mathrm{C}(\mathrm{n}=30)$ & $1.28 \pm 0.15$ & $15.96 \pm 3.54$ & $1.04 \pm 0.02$ \\
\hline
\end{tabular}

Group $A=21-30$ years of adults (Control), Group $B=51-60$ years of elderly subjects (study), Group $C=$ 61-70 years of elderly subjects (study). $* * *=\mathrm{p}<0.001, * *=\mathrm{p}<0.01$, ns $=$ not significant, $\mathrm{n}=$ number of subjects.

Table IV: Assessment of sympathetic nerve functions by diastolic blood pressure response to sustained handgrip in different groups (n-90)

\begin{tabular}{lccc}
\hline Groups & \multicolumn{3}{c}{$\begin{array}{c}\text { Diastolic blood pressure } \\
(\mathrm{mm} \text { of Hg) }\end{array}$} \\
\cline { 2 - 4 } & Before handgrip & After handgrip & Increase after handgrip \\
\hline $\mathrm{A}(\mathrm{n}=30)$ & $66 \pm 7.85$ & $86 \pm 7.75$ & $20 \pm 2.75$ \\
$\mathrm{~B}(\mathrm{n}=30)$ & $72 \pm 8.64$ & $90 \pm 8.20$ & $18 \pm 3.90$ \\
$\mathrm{C}(\mathrm{n}=30)$ & $73 \pm 10.03$ & $91 \pm 10.23$ & $18 \pm 2.89$ \\
\hline
\end{tabular}

\section{Statistical Analysis:}

A vs B $0.015 *$

$\mathrm{A}$ vs $\mathrm{C} \quad 0.033^{*}$

B vs C $0.749^{\text {ns }}$

Group $A=21-30$ years of adults (Control), Group $B=51-60$ years of elderly subjects (study), Group $C=61-70$ years of elderly subjects (study). ${ }^{*}=\mathrm{p}<0.05$, ns $=$ not significant, $\mathrm{n}=$ number of subjects. 
Table V: Assessment of sympathetic nerve functions by systolic blood pressure response to standing in different groups (n-90)

\begin{tabular}{lccc}
\hline Groups & \multicolumn{3}{c}{ Systolic blood pressure (mm of Hg) } \\
& Lying & After standing & Fall after standing from lying \\
\hline $\mathrm{A}(\mathrm{n}=30)$ & $111 \pm 7.90$ & $108 \pm 8.04$ & $3.53 \pm 3.28$ \\
$\mathrm{~B}(\mathrm{n}=30)$ & $117 \pm 9.51$ & $111 \pm 13.36$ & $6.27 \pm 6.59$ \\
$\mathrm{C}(\mathrm{n}=30)$ & $115 \pm 8.39$ & $108 \pm 11.22$ & $7.27 \pm 7.21(0-26)$ \\
\hline
\end{tabular}

\section{Statistical Analysis:}

$\begin{array}{ll}\text { A vs B } & 0.079^{\text {ns }} \\ \text { A vs C } & 0.017^{*} \\ \text { B vs C } & 0.517^{\text {ns }}\end{array}$

Results are expressed as mean $\pm \mathrm{SD}$. One-way ANOVA (Post Hoc) and independent sample $t$ tests were done as the test of significance.

Group $\mathrm{A}=21-30$ years of adults (Control), Group $\mathrm{B}=51-60$ years of elderly subjects (study), Group $\mathrm{C}=61-70$ years of elderly subjects (study). ${ }^{*}=\mathrm{p}<0.05$, ns $=$ not significant, $\mathrm{n}=$ number of subjects.

Table VI: Distribution of the subjects by autonomic nerve functions scoring in different study groups (n-90)

\begin{tabular}{|c|c|c|c|}
\hline $\begin{array}{l}\text { Autonomic nerve } \\
\text { function }\end{array}$ & $\begin{array}{c}\text { Group-A } \\
(\mathrm{n}=30) \\
\text { No. } \quad(\%)\end{array}$ & $\begin{array}{c}\text { Group-B } \\
(\mathrm{n}=30) \\
\text { No. }(\%)\end{array}$ & $\begin{array}{c}\text { Group-C } \\
(\mathrm{n}=30) \\
\text { No. }(\%)\end{array}$ \\
\hline Normal & $30(100)$ & $27(90)$ & $23(76.66)$ \\
\hline Early involvement & 0 & $3(10)$ & $6(20)$ \\
\hline Definite involvement & 0 & 0 & $1(3.34)$ \\
\hline Severe involvement & 0 & 0 & 0 \\
\hline Total autonomic neuropathy & 0 & $3 \quad(10)$ & $7 \quad(23.34)$ \\
\hline
\end{tabular}

Group-A : 21-30 years of adults (Control), Group-B : 51-60 years of elderly subjects (group-C : 61-70 years of elderly subjects.

\section{Discussion}

In the present study the mean value and range of parasympathetic nerve function that is valsalva ratio, HR response to deep breathing an HR response to standing $\left(30^{\text {th }}: 15^{\text {th }}\right)$ were gradually decreased in elderly groups compared to that of adult. Similar observations were also made by other workers. ${ }^{4,11,23-26}$

For assessment of sympathetic functions, the rise in diastolic blood pressure after handgrip was lower in 51-60 and 61-70 years age groups than that of 21-30 years. Other workers also observed similar results. ${ }^{22,27}$ Another sympathetic function tests that is fall of systolic BP after standing was more decrease in 51-60 and 61-70 years age groups than that of 21-30 years. This finding is in agreement with other workers. ${ }^{20,26,28}$

In this study, distribution of subjects by scoring of the autonomic nerve function (ANF) has 
shown that, $100 \%$ healthy adult subjects had normal ANF status and 90\% subjects of 51-60 years and 77\% subjects of 61-70 years had normal autonomic nerve functions. No similar data are available to compare this finding. The degree of involvement of Autonomic neuropathy was also evaluated by scoring of the results of tests of pasympathetic and sympathetic function. $20 \%$ subjects of 61-70 years were in the stage of early involvement of autonomic neuropathy while this percentage was relatively lower (10\%) in 51-60 years age group. One study observed early involvement of ANF in $12.6 \%$ of healthy elderly person. ${ }^{8}$ Definite involvement of ANF was observed in $3.34 \%$ in $61-70$ years and none in 51 60 years of age groups in this study. Almost similar findings were reported by other observers ${ }^{8}$.. It has been reported that autonomic nerve dysfunction had been present in $16.45 \%$ of healthy elderly subjects. ${ }^{8}$

These above finding indicate that both parasympathetic and sympathetic nerve functions are impaired in old age. However, the exact mechanism involved for impairment of this nerve function in the elderly subject of present series cannot elucidate from this study. According to suggestions made by different investigations, the probable mechanism of impairment of parasympathetic functions are reduced due to loss of vagal tone in old age, ${ }^{29,30}$ decreased baro-reflex activity ${ }^{31}$ and vagal damage. ${ }^{4}$ Impairment of sympathetic nerve functions are may be due to reduced $\beta$ and $\beta$ adrenergic activity on heart and blood vessels in old age. ${ }^{12,13}$ There may be increased norepinephrine level with advancement of age but its responsiveness to target organ is reduced. ${ }^{32}$

The results of the present study suggest attenuated cardiac autonomic nerve activity with advancement of age may be responsible for the involvement of more number of elderly subjects with impairment of ANF.

\section{Conclusion}

From this study, it can be concluded that cardiac autonomic nerve function is impaired with aging process which is characterized by scoring of autonomic nerve function.

\section{Author affiliations}

1. Taslima Islam, Associate Professor, department of Physiology, Medical College for Women, Uttara. Dhaka.

2. Noorzahan Begum, Professor, Department of Physiology, Bangabandhu Sheikh Mujib Medical University (BSMMU), Bangladesh. Email: noorzahan52@gmail.com

3. *Sultana Ferdousi, Associate Professor, Department of Physiology, Bangabandhu Sheikh Mujib Medical University (BSMMU), Bangladesh.Email: sferdousi ratna@gmail.com.Tele:+88-01819707160

* for correspondence

\section{References}

1. Ewing DJ. Cardiovascular reflexes and autonomic neuropathy. Clin Sci Mol Med. 1978; 55:312-27.

2. Francine GS, Cohn JN. Cardiac failure and the autonomic nervous system. In: Bannister SR, Mathias CJ editors. Autonomic failure, A textbook of clinical disorders of the autonomic nervous system. $3^{\text {rd }}$ Edition. New York: Oxford University press; 1992, 822-38.

3. Maser RE, Lenhard MJ, Pecherney GS. Cardiovascular autonomic neuropathy and the clinical significance of its determination. J Endol. 2000; 10:27-33.

4. Grubb BP. Syncope in the older patient. Hellenic J cardiol. 2003; 44:235-42.

5. Jones PP, Christou DD, Jordan J, Seals DR. Baroreflex buffering is reduced with age in healthy men. Circulation. 2003; 107:1770-74.

6. Lipsitz LA. Syncope in the elderly. Ann intern med. 1983; 99:92-105.

7. Ingal TJ, McLeod JG, O'Brien PC. The effect of aging on autonomic nervous system function. Aust NZ J Med. 1990; 20 (4): 570-77.

8. O' Brien IAD, O' Hare P, Carrall KIM. Heart rate variability in healthy subjects: effect of age and derivation of normal ranges for test of autonomic function. Br. Heart J. 1985; 55:348-54

9. Linares OA, Halter JB. Sympathochromaffin system activity in the elderly. J Am Geriatr 1987; $35: 448-53$. 
10. Morrow LA, Linarer OA, Hill TJ. Influence of age in plasma clearance mechnaism for epinephrine and nor-epinephrine in humans. J Clin Endocrinol Metab 1985; 65:508-11.

11. Supiano MA, Linares OA, Smith MJ. Age related differences in norepinephrine: effect of posture and sodium restricted diet. Am J Physiol 1990; 259:422-31

12. Pan HYM, Blaschke TF. Decline in â-adrenergic receptor mediated vascular relaxation with aging in man. J Pharm Exptl Therap 1986; 239: 802-07.

13. Hogikyan RV, Supiano MA. Arterial á adrenergic responsiveness is decreased and SNS activity is increased in older humans. Am J Physiol 1994; 266: E 717-24.

14. Mathias CJ, Bannister R. Investigation of autonomic disorders. In: Bannister SR, Mathias CJ, editors Autonomic failure, A text book of clinical disorders the autonomic nervous system. $3^{\text {rd }}$ ed. New York: Oxford University press; 1993, 255-90.

15. Ewing DJ, Clarke BF. Diagnosis and management of diabetic autonomic neuropathy. Br Med J 1982; 285: 916-18.

16. Islam T,Begum N, Begum S, Ferdousi S, Ali T. Evaluation of Parasympathetic Nerve Function Status in Healthy Elderly Subjects. J Bangladesh Soc Physiol. 2008; Dec(3):23-28

17. Islam T,Begum N. Age related changes to cardiovascular sympathetic function assessed by blood pressure response to sustained hand group Journal for the medical college for women and hospital.2008;6(2):69-73.

18. Shimaa K, Kitazumi T, Hisakazu O, Sadakane N. Effect of age and blood pressure on the cardiovascular responses to the valsalva maneuver. J Am Geriatr Soc. 1986; 34: 431-34.

19. Johnson RH. Aging and autonomic nervous system. In: Bannister SR, Mathias CJ. editors Autonomic failure, A textbook of clinical disorders of the autonomic nervous system. $3^{\text {rd }}$ ed. New York: Oxford university press; 1992, 882-903.

20. Cubulski G. Influence of age on the immediate cardiovascular response to orthostatic maneuver. Euro J Appl physiol. 1996; 73 (6): 563-72.
21. Rajerdra AU, Kannathal N, Sing OW, Plng LY, Chua T. Heart rate analysis in normal subjects of various age groups. J Biomed Engin. 2004; 3 (24): 1-8.

22. Chu TS, Tasi TJ, Lai Chen WY. Evaluation of cardiovascular autonomic function tests in normal subjects. J Formosan Med Assoc. 1998; 88: 40406.

23. Lavin AB. A simple tests of cardiac changes induced by the valsalva maneuver. Am J cardiol. 1966; 18: 90-99.

24. Smith SA. Reduced sinus arrhythmia in diabetic autonomic neuropathy: diagnostic value of an age related normal range. Br Med J. 1982; 285: 15991601 .

25. Maddens M, Lipstiz LA, Wei JY, Pluchino FC, Mark P. Impaired heart rate response to cough and deep breathing in elderly patients with unexplained syncope. Am J cardiol. 1987; 60:1368-72.

26. Dambrink JHA. Othostatic regulation of blood pressure. A comparative study in young and old subjects. Clin Sci. 1991; 81:51-58.

27. Gautschy B, Weidmann P, Gnadinger MP. Autonomic function tests as related to age and gender in normal man. J Klin Wocherschr 1986; 64 (11): 499-05.

28. Caird FI, Andrew GR, Kennedy RD. Effect of posture on blood pressure in the elderly Br. Heart J $1985 ; 35$ : 527-530.

29. Wieline W, Vandrederode JEM, Derijk LG, Borst C, Dunning AJ. Reflex control of HR in normal subjects in relation to age, A data base for cardiac vagal neuropathy. Diabetologia. 1982; 22: 163-66.

30. Mancia G, Ferrari A, Gregorini L, Parati G, Pomidossi G, Bertinieri G, Grassi G. Blood pressure and HR variability in normotensive and hypertensive human beings. Circ Res. 1983; 53: 96-104.

31. Shi X, Gallagher KM, O' Connor W, Foreman BH. Arterial and cardiopulmonary baroreflex in 60 to 69 vs 18 - 36 years old humans. J Appl physiol. 1996; 80: 1903-10.

32. Seals DR, Esler MD. Human aging and the sympatho adrenal system. J Physiol 2000; 528: 407-17. 